\title{
Sağlık Çalışanlarının Bilgi Teknolojileri ve Yeniliklerine İlişskin Davranışsal Tutumunun Utaut-2 Teorisiyle İncelenmesi
}

\author{
Investigation of Health Professionals Behavioral Attitude Regarding Information Technologies and Innovations \\ With the Utaut-2 Theory
}

\author{
Yiğit Kerem YILDIZ ${ }^{1}$, Hasan DİNÇER ${ }^{2}$
}

\section{ÖZ}

Sağlık hizmetlerinin daha kaliteli sunulması gibi amaçların karşılanabilmesi için sağlık çalışanlarının bilgi teknolojilerine yönelik tutumları değerlendirilmelidir. $\mathrm{Bu}$ değerlendirmeler, sağlık çalışanlarının sağlıkta belirlenen amaçların gerçekleştirilebilmesine ve gelecekte yapılabilecek muhtemel yeniliklere hazır olmalarına yardımcı olacaktır. Çalışmanın amacı, sağlık çalışanlarının bilgi teknolojileri ve yeniliklerine ilişkin davranışsal tutumlarını UTAUT-2 Teorisi ile incelemektir. Bu çalışma, çeşitli teknolojilere yönelik davranışsal tutumların incelenmesinde siklıkla kullanılan UTAUT-2 ile elde edilen sonuçların yanı sıra bilgi teknolojilerine yönelik yapılabilecek yeniliklere ilişkin tutumu da değerlendirerek literatüre bir yenilik getirmektedir. Araştırmada, Yapısal Eşitlik Modeli kurularak gerekli istatistiksel analizler yapılmıştır. Yapilan incelemeler neticesinde, performans beklentisi $(\beta=0,37, p<0,01)$ ve alışkanlığın $(\beta=0,75$, $\mathrm{p}<0,001)$ sağlık çalışanlarının bilgi teknolojileri ve yeniliklerine ilişkin davranışsal tutumları üzerinde anlamlı ve olumlu bir etkisi olduğu bulunmuştur. Çaba beklentisinin $\quad(\beta=-0,25, \quad \mathrm{p}<0,05), \quad$ hedonik motivasyonun $(\beta=-0,13, p<0,05)$ sağlık çalışanlarının bilgi teknolojileri ve yeniliklerine ilişkin davranışsal tutumları üzerinde anlamlı etkisi bulunmasına rağmen bu etkinin negatif yönlü olduğu bulunmuştur. Sosyal etkinin $(\beta=0,05, \quad p>0,05)$, kolaylaştırıcı koşulların $(\beta=0,00, p>0,05)$, algilanan fiyat değerinin $(\beta=0,09$, $\mathrm{p}>0,05)$ sağlık çalışanlarının bilgi teknolojileri ve yeniliklerine ilişkin davranışsal tutumları üzerinde anlamlı ve olumlu bir etkisinin olmadığı bulunmuştur. Gelecekte, sağlık çalışanlarının teknolojilere yönelik tutumlarının değerlendirilmesinin yaygınlaşacağ beklenilmektedir.

Anahtar Kelimeler: Bilgi Teknolojisi, Sağlık, Sağlık Bilgi Teknolojisi, Sağlık Personeli.

\begin{abstract}
Health professionals attitudes towards information technologies should be evaluated in order to meet goals such as presenting better quality of health services. These evaluations will help health professionals to achieve the goals that determined in health and to be ready for possible innovations that may be made in the future. The aim of study is to examine the behavioral attitudes of health professionals towards information technologies and innovations with the UTAUT-2 Theory. This study brings an innovation to the literature by evaluating the results obtained with UTAUT-2 which is frequently used in the examination of behavioral attitudes towards various technologies, as well as the attitude towards innovations that can be made towards information technologies. Necessary statistical analyzes were made by establishing the Structural Equation Model in the research. As result of examinations, it was found that performance expectancy $(\beta=0.37, p<0.01)$ and habit $(\beta=0.75$, $\mathrm{p}<0.001)$ had significant and positive effect on behavioral attitude to the information technologies and innovations by health professionals. Although effort expectancy $(\beta=-0.25, \quad p<0.05)$, hedonic motivation $(\beta=-0.13, p<0.05)$ had significant effect on health professionals behavioral attitude to the information technologies and innovations, this effect was found to be negative. It was found that social influence $(\beta=0.05, \quad p>0.05)$, faciliating conditions $(\beta=0.00$, $\mathrm{p}>0.05)$, perceived price value $(\beta=0.09, \mathrm{p}>0.05)$, had no significant and positive effect on health professionals behavioral attitude to the information technologies and innovations. It is expected that the evaluations of health professionals regarding their attitudes towards technologies will become widespread in the future.
\end{abstract}

Keywords: Information Technology, Health, Health Information Technology, Health Personnel.

\footnotetext{
Bu çalışma, birinci yazarın doktora tezinden üretilmiştir.

Doktora Öğrencisi, Yiğit Kerem YILDIZ, Sağlık Yönetimi, İstanbul Medipol Üniversitesi Sağlık Bilimleri Enstitüsü, yigitkeremyildiz93@gmail.com, ORCID: 0000-0002-2976-9169

${ }^{2}$ Prof. Dr., Hasan DİNÇER, İşletme, İstanbul Medipol Üniversitesi İşletme ve Yönetim Bilimleri Fakültesi, hdincer@medipol.edu.tr, ORCID: 0000-0002-8072-031X
} 


\section{GIIRIŞ}

Günümüz dünyasında, bilgi teknolojileri uygulamaları ile sistemleri kendisini hissettirmektedir. Bilgi teknolojilerinin sağlik alanında olmasiyla beraber bazı avantajlar elde edilebilmesinden dolayı bu tür teknolojilere yönelik yatırımlar dünya çapında devam etmektedir. ${ }^{1-3}$

Bir ülkede bilgi teknolojilerinin sağllk sistemi içerisinde kullanım sıklığını ve önemini belirleyen en temel göstergelerden birisi, bir ülkenin sağlıktaki kaynaklarıdır. Bu kaynakların başında insan kaynağı gelmektedir. Türkiye gibi gelişmekte olan ülkelerin bilgi teknolojilerine yönelik uygulamaların yaygın bir şekilde kullanılmasının ve çok büyük bir önem arz etmesinin temel sebeplerinden birisi, sağlık çalışanlarının ve hekimlerin yeterli düzeyde olmamasıdır. ${ }^{4}$ Türkiye'de 2002 yılında toplam 378551 sağlık çalışanı varken 2018 yılında bu rakam 1016401 kişiye çıkmıştır. ${ }^{5}$ Buradan anlaşılacağı üzere Türkiye'deki sağlık insan gücünün yıllar geçtikçe arttığ1 görülmektedir. Sağlıkta yer alan insan gücünün, hizmete ihtiyaç duyan kişilere yetişebilme ve onlara tam anlamıyla sağlık hizmetlerini sunabilmeleri gerekir. Bunu öğrenebilmek için sağlık insan gücünün uluslararası boyutta karşılaştırmalı olarak değerlendirmesinin yapılması gerekir. Türkiye'nin 2018 yılında 100000 kişi başına düşen hekim sayıs1 187'dir. Ancak OECD ülkelerinin ortalaması olan 348 ile Avrupa Birliği ülkelerinin ortalaması olan 371 değerlerinin altındadır. Türkiye'nin 100000 kişi başına düşen eczacı sayısı 39'dur. Burada belirtilen değer, OECD ortalaması olan 83 ile Avrupa Birliği ülkelerinin ortalaması olan 87 değerlerinin altındadır. Türkiye'nin 100000 kişi başına düşen hemşire ve ebe sayısı 301'dir. Fakat buradaki değer OECD ortalaması olan 938 ile Avrupa Birliği ülkelerinin ortalaması olan 841 değerlerinin altındadır. ${ }^{5}$ Buradaki değerler, Türkiye'deki sağlık çalışanları sayısındaki artışa rağmen kişi başına düşen sağlık personeli sayısının yeterli düzeyde olmadığını göstermektedir.
Bilgi teknolojileri özellikle hasta popülasyonun giderek arttığı, kısıtlı kaynakların bulunduğu ortamlarda sağlik çalışanlarının zorlu koşullarda yapmakta oldukları işleri başarılı bir şekilde yerine getirebilmelerine yardımcı olmaktadır. Ancak bilgi teknolojilerinin sağlık alanı açısından büyük bir önem taşımasına rağmen ikinci plana atılmış bir nokta bulunmaktadır. $\mathrm{Bu}$ nokta ise sağlık çalışanlarının sıklıkla kullanmakta oldukları bilgi teknolojilerine yönelik tutumlarının değerlendirilmesidir. Sağlık çalışanları yalnızca sağlık konusunda birinci kaynak olmalarının dışında e-Sağlık gibi bilgi teknolojilerinin etkililiğinde önemli bir rolü bulunmaktadır. ${ }^{6,7} \mathrm{Bu}$ yüzden sağlık çalışanlarının bilgi teknolojilerine yönelik tutumlarının değerlendirilmesi, kuruluşlar tarafindan yapılan yatırımların başarı ihtimalinin artması, sağlık hizmetlerinin başarılı, etkili, verimli ve kaliteli bir şekilde sunulması açısından önemlidir. Tutuma yönelik değerlendirmenin yapılması için çeşitli teoriler mevcuttur. Sağlık çalışanlarının bilgi teknolojileri dâhil olmak üzere kullanmakta oldukları teknolojilere yönelik tutumlarını incelerken; Sebepli Eylem Teorisi, Planlı Davranış Teorisi, İnovasyonun Yayılması Teorisi, Teknoloji Kabul Modeli, Sosyal Biliş Teorisi gibi teoriler kullanılmaktadır. ${ }^{8}$

Kısaca özetlemek gerekirse, sağlıkta bilgi teknolojilerine yönelik yatırımlar ve atılımlar devam etmektedir. Ancak bu atılımlar yapılırken sağlık çalışanlarının bilgi teknolojilerine ilişkin tutumlarına yönelik değerlendirmeler ikinci plana atılmaktadır. $\mathrm{Bu}$ tür değerlendirmelerin yapılması için geliştirilen teoriler arasında ön plana çıkan UTAUT Teorisi'dir. UTAUT Teorisi'nin ilk versiyonuyla yapılan çalışmaların fazlasıyla bulunmasina rağmen UTAUT-2 ile sağlik çalışanlarına yönelik yapılan çalışma sayısı oldukça azdır. Ayrıca UTAUT'un herhangi bir versiyonuyla yapılan çalışmalarda yalnızca mevcut teknolojiye yönelik tutumları değil aynı zamanda o teknolojiye yönelik yeniliklere ilişkin tutumlar hakkında sınırlı da olsa değerlendirme yapılabilir. 
Çünkü teoriyi oluşturan boyutların inovasyon literatüründe karşılığ rağmen literatürdeki çalışmalar, elde etmiş oldukları sonuçları inovasyon açısından değerlendirmemektedir. Yapılan bu çalışma, literatürde yer alan eksiklerin giderilmesi dışında, sağlık çalışanlarının bilgi teknolojilerine yönelik tutumlarını UTAUT-2 Teorisi ile değerlendirerek, sağlı çalışanlarının kullanmakta oldukları bilgi teknolojilerinde olumlu ve olumsuz gördükleri boyutların ortaya çıkarılarak sağlik bilimleri ve bilgi teknolojileri literatürüne katkıda bulunmaktadır.

$\mathrm{Bu}$ çalışmanın amacı, sağlık çalışanlarının bilgi teknolojileri ve yeniliklerine ilişkin davranışsal tutumunun UTAUT-2 Teorisi ile incelenmesidir.

\section{MATERYAL VE METOT}

\section{Araştırmanın Örneklemi ve Verilerin Toplanması}

$\mathrm{Bu}$ çalışmada araştırmanın evrenini, Medipol Sağlık Grubu bünyesinde ve İstanbul'da yer alan Medipol Sefaköy Hastanesi, Medipol Çamlica Hastanesi ve Medipol Mega Hastanesi'nde görev yapan sağlık çalışanları oluşturmaktadır. Araştırmada örneklem kriteri olarak, araştırmanın uygulandığı Medipol Sefaköy Hastanesi, Medipol Çamlıca Hastanesi ve Medipol Mega Hastanesi'nde görev yapıyor olmaları ve kurumsal e-mail adresleri bulunmalarıdır.

2020 Y1lı'nın Kasım-Aralık ayları arasında Medipol Sağlik Grubu bünyesinde seçilen üç hastanede görev yapan sağlik çalışanlarının bilgi teknolojileri ve yeniliklerine ilişkin davranışsal tutumları değerlendirilmiştir. $\mathrm{Bu}$ değerlendirmelerin yapılması için araştırmanın verileri, online anket ve yüz yüze görüşme yöntemiyle toplanmıştır.

$\mathrm{Bu}$ araştırmaya belirtilen aralıklarda toplam 418 kişi katılmıştır. Ancak araştırmanın uygulanması için kurulacak olan Yapısal Eşitlik Modeli'nin ve verilerin normal dağılımının sağlanabilmesi için araştırmaya katılanlardan 10 kişi veri setinden çıkartılarak araştırmaya yönelik analizler 408 kişi üzerinden yapılmıştır.

\section{Ölçüm Modeli}

Araştırmada yer alan hipotezlerin test edilmesi için hazırlanan anketin ve modelin oluşturulmasında UTAUT'un ikinci versiyonu kullanılmıştır. ${ }^{9}$ Hazırlanan anket toplamda yedi sorudan oluşmaktadır. $\mathrm{Bu}$ soruların ilk altısı araştırmaya katılan sağlık çalışanlarının tanımlayıcı özelliklerinin öğrenilmesi amacıyla sorulmuştur. Yedinci soru ise UTAUT-2 Teorisi'ni oluşturan değişkenleri temsil eden toplam 28 öğeyi içermektedir. Burada belirtilen 28 öğenin 4'ü performans beklentisine (PB), 4'ü çaba beklentisine (ÇB), 3'ü sosyal etkiye (SE), 4'ü kolaylaştırıcı koşullara (KK), 3'ü algılanan fiyat değerine (FD), 3'ü hedonik motivasyon (HM) kavramına, 4'ü alışkanlığa (AL) yöneliktir. Geriye kalan 3'ü ise araştırmanın bağımlı değişkeni olan davranışsal niyet (DN) kavramına yöneliktir. Ayrıca burada belirtilen öğeler için "1-Kesinlikle Katılmıyorum", "5-Kesinlikle Katıliyorum" şeklinde beşli likert ölçeği kullanılmıştır.

\section{İstatistik Analizi ve Verilerin Ölçüm Yöntemi}

Araştırmada toplanan verilerin analizinin gerçekleştirilmesi için SPSS 20,0 ve AMOS 24,0 ile Microsoft Excel programları kullanılmıştır. SPSS Programı, araştırmaya katılanların tanımlayıcı istatistik analizleri, normallik testi, Cronbach Alpha'yı ve değişkenler arası korelasyon durumunu öğrenmek için, AMOS Programı ise araştırmada oluşturulacak olan Yapısal Eşitlik Modeli'nin geçerli ve güvenilir olduğunu model uyum endeksi değerleri üzerinden değerlendirilmesi ve hipotez testlerinin yapılabilmesi için kullanılmıştır. Excel Programı, CR (Bileşik Güvenilirlik) ve AVE (Ayıklanmış Ortalama Varyans) değerlerinin hesaplanabilmesi için kullanılmıştır.

Araştırmanın geçerlilik ve güvenilirlik analizlerinin yapılması için doğrulayıcı 
faktör analizi tercih edilmiştir. Yapısal Eşitlik Modeli kurularak analizlerin yapılması için bazı model uyum kriterlerinin karşılanmış olması gerekir. Burada belirtilen uyum kriterleri aşağıdaki şekilde sıralanmıştır:

-Ki kare/Serbestlik derecesi ( $\chi 2 / \mathrm{df})$ : Genel model uyum kriterlerinden birisi olan bu kriter, ki kare değerinin serbestlik derecesine bölünmesiyle elde edilir. ${ }^{10}$ Burada belirtilen endeksin, $0 \leq \chi 2 / \mathrm{df} \leq 2$ arasinda olmasi iyi uyumu, $2<\chi 2 / \mathrm{df} \leq 3$ arasinda olmasi ise kabul edilebilir uyumu temsil eder. ${ }^{11}$

-GFI (Goodness of Fit): Mutlak model uyum endeksleri içinde yer alan GFI, ki kare değerinin veri setinin büyümesinden kaynaklanan artış problemini ortadan kaldırmak amacıyla ortaya çıkmıştır ve örnek büyüklüğünden fazla etkilenmez. ${ }^{10}$ Burada belirtilen endeksin, $0,90 \leq \mathrm{GFI}<0,95$ arasinda olması kabul edilebilir uyumu temsil eder. ${ }^{11}$

-AGFI (Adjustment Goodness of Fit): Mutlak model uyum endeksleri arasında yer alan AGFI, GFI değerinin serbestlik derecesinden filtrelenmiş versiyonudur. ${ }^{10}$ AGFI aynı zamanda, daha az kısıtlanmış GFI değeri olarak görülebilir. Burada belirtilen endeksin, $0,85 \leq \mathrm{AGFI}<0,90$ arasinda olması kabul edilebilir uyumu temsil eder. ${ }^{11}$

•NFI (Normed Fit Index): Karşılaştırmalı uyum endekslerinden birisi olan NFI, oluşturulan modelin ki kare değeri ile ölçülen değişkenlerin ilişkisi bulunmayan modeli temsil eden sıfır modeline ait ki kare değerini karşılaştırarak ortaya çıkan bir değerdir. ${ }^{10}$ Burada belirtilen endeksin, $0,90 \leq \mathrm{NFI}<0,95$ arasında olması kabul edilebilir uyumu temsil etmektedir. ${ }^{11}$

-TLI (Tucker-Lewis Index): Karşılaştırmalı uyum endekslerinden birisi olan TLI'yi açıklamadan önce bahsedilmesi gereken bir nokta bulunmaktadır. TLI, literatürde bazen NNFI (Non-Normed Fit Index) olarak da bilinir ve veri seti büyüklüğü ya da diğer adıyla örneklem büyüklüğünden kaynaklanan bazı etkilerin yok edilmesi için ortaya çıkmıştır. ${ }^{10}$ TLI, oluşturulan modelin karmaşıklaşması ile düşük örneklem durumlarında düşük değer göstermeye meyillidir. ${ }^{10}$ Burada belirtilen endeks için iki referans değeri kabul edilebilir olarak belirtilmektedir. Bunlardan birisi, TLI $>0,95$ diğeri ise TLI $>0,80$ 'dir. ${ }^{10}$ Burada belirtilen referans değerlerinin her ikisi de kabul edilebilir uyumu temsil etmektedir.

-CFI (Comparative Fit Index): Karşılaştırmalı uyum endekslerinden birisi olan CFI, örnek büyüklügünü dikkate alan, Yapısal Eşitlik Modeli çalışmalarında yaygın olarak kullanılan, küçük örneklerle yapılan çalışmalarda daha iyi sonuç veren, NFI değerinin daha gelişmiş bir cinsidir. ${ }^{10}$ Burada belirtilen endeks için $\mathrm{CFI}>0,90$ kabul edilebilir uyumu temsil etmektedir. ${ }^{12}$

-RMSEA (Root Mean Square Error of Approximation): Karşıllaştırmalı uyum endekslerinden birisi olan RMSEA, serbestlik derecesi başına gözlemlenen kovaryans matrisiyle modu belirten kabul edilmiş kovaryans matrisi arasındaki farkı temsil eder. ${ }^{13,14}$ RMSEA, kurulan bir modelde yer alan değişkenler ile ifadelerin miktarı arttıkça etkilenen ve az sayıda ifadeyi destekleyen bir yapısı vardır. ${ }^{10}$ RMSEA endeksi için $0 \leq \mathrm{RMSEA} \leq 0,05$ iyi uyumu, $0,05<$ RMSEA $\leq 0,08$ kabul edilebilir uyumu temsil etmektedir. ${ }^{11}$

-SRMR (Standardized Root Mean Square Residual): SRMR, gözlemlenen ve kabul edilmiş kovaryans matrisleri arasındaki standartlaştırılmış artıkların ortalamasını temsil etmektedir. ${ }^{13,14}$ Burada belirtilen endeks için $0 \leq \mathrm{SRMR} \leq 0,05$ iyi uyumu, $0,05<$ SRMR $\leq 0,10$ kabul edilebilir uyumu temsil etmektedir. ${ }^{11}$

Doğrulayıcı faktör analizi kapsamında model uyum kriterlerinin incelenmesinin ardindan CR, AVE ve Cronbach Alpha değerleri ile değişkenler arasındaki korelasyon durumunun da incelenmesi gerekir. Burada belirtilenlerin yapılmasının ardından doğrulayıcı faktör analizi tamamlanmış olacaktır. Literatürde yapılan çalışmalardaki doğrulayıcı faktör analizi değerlendirmelerinde de bu uygulamalar yapılmaktadır. CR ve AVE değerleri, Şekil 1 'de belirtilen formüllere göre hesaplanmıştır. 


\section{Şekil 1. CR ve AVE Formülü ${ }^{15}$}

$\mathbf{n}=$ Ífade sayıs

$\mathbf{L}=$ Standardize faktör yükü

$\mathbf{e}=$ Hata varyans 1

Araştırmada yapılacak olan doğrulayıcı faktör analizi kapsamında incelenecek olan değerlerin tıpkı model uyum endekslerinde olduğu gibi kabul edilebilir bir referans değeri bulunmaktadır.

Normallik testi kapsamında verilerin normal dağıldığını kabul edebilmek için değişkenlere ait ifadelerin çarpıklık ve basıklık değerlerinin analiz edilmesi gerekir. Değişkenlere ait ifadelerin çarpıklık ve basıklık değerlerinin +2 ve -2 arasında olması gerekir. ${ }^{16}$

Değişkenlere ait ifadelerin faktör yüklerinin, en az 0,50 ve üzeri olması gerekir. ${ }^{15}$ Ayrıca CR'nin, 0,70 ve üzeri, AVE'nin 0,50 ve üzeri, Cronbach Alpha değerinin ise 0,70 ve üzeri olması gerekir. ${ }^{15}$

Doğrulayıcı faktör analizi kapsamında son olarak değişkenler arasındaki korelasyon durumu değerlendirilmelidir. Burada belirtilen değişkenler arasındaki korelasyon değerinin $0,85^{\prime}$ in altında olması gerekir. ${ }^{17}$

\section{Araştırmanın Kısıtlılıkları}

Araştırmanın kısıtlılıklarında ilk olarak, bu çalışmada kullanılan UTAUT-2 Teorisi normalde yer alan; yaş, cinsiyet, mesleki deneyim, eğitim seviyesi düzenleyici değişkenleri kullanılmamıştır. Çünkü araștırmanın amacına bağlı kalarak sağlık çalışanlarının bilgi teknolojileri ve yeniliklerine ilişkin davranışsal tutumlarının incelenmesi ve bu incelemeler neticesinde elde edilen sonuçların yorumlanmasına odaklanılmış olmasıdır.

İkinci olarak, bu çalışmada elde edilen bulguları karşılaştırmak için yapılan literatür taramasında, ağırlıklı olarak UTAUT'un ikinci versiyonunun kullanıldığı çalışmalar dikkate alınmıştır.

Üçüncü olarak, literatür taraması yapılırken yalnızca sağlık çalışanlarının veya araştırma katılımcıları arasında sağlık çalışanlarının bulunduğu çalışmalar dahil edilmiştir.

Dördüncü olarak araștırmadaki sonuçlar, Medipol Sağlık Grubu bünyesinde yer alan sağlık çalışanlarından elde edilmiştir. Bundan dolayı, burada belirtilen sonuçlara genelleme yapilırken dikkat edilmesi gerekir.

\section{Araştırmanın Etik Yönü}

Araştırmanın gerçekleştirilebilmesi için İstanbul Medipol Üniversitesi Girişimsel Olmayan Klinik Araştırmalar Etik Kurulu'ndan (Karar No: 17.09.2020/ 10840098-772.02-E.47857) gerekli onay alınmıştır.

Araştırmanın uygulanacağ İstanbul Medipol Üniversitesi Sağlık Bilimleri Enstitüsü'nün hazırlamış olduğu belgenin (Belge No: 25.09.2020/31034136302.08.01-E.49846), Medipol Sağlık Grubu bünyesindeki hastanelerin başhekimlikleri tarafından sslak imzaları alınarak kurum izinleri alınmıştır.

\section{BULGULAR VE TARTIŞMA}

\section{Tanımlayıcı Bulgular}

Verilerin normal dağılıma uygun olup olmadığı, çarpıklık ve basıklık analiziyle incelenmiştir. Yapılan çarpıklık ve basıklık analizi sonuçlarına göre veriler normal dağ 11 lım göstermektedir.

Verilerin normal dağıldığının kanıtlanmasının ardından, araştırmaya katılan sağlık çalışanlarının yaş, cinsiyet, çalıştıkları kuruluş gibi tanımlayıcı özelliklerine yönelik tanımlayıcı istatistik analizleri yapılmıștır. Yapılan tanımlayıc1 istatistik analizinin sonucu Tablo 1'de özetlenmiştir.

Tablo 1'e bakıldığında araştırmaya katılanların \%72,3'ünün kadın olduğu görülmektedir. Ayrıca katılımcıların önemli bir kısmının 20-24 (\%40,4) yaş aralığında 
olduğu görülmektedir. Katılımcıların eğitim seviyesine bakıldığında büyük bir kısmı ön lisans $\quad(\% 47,1)$ mezunudur. Sağlık çalışanlarının mesleki deneyimlerine bakıldığında, katılımcıların \%30,9'unun 2-3 y1l olduğu görülmektedir. Son olarak çalışmış oldukları kuruluşlara bakıldığında araştırmaya katılanların, \%50'si Medipol Mega Hastanesi'ndendir.

Tablo 1. Araştırmaya Katılanların Tanımlayııı Özellikleri

\begin{tabular}{|c|c|c|}
\hline Değişkenler & Sayı & $\%$ \\
\hline \multicolumn{3}{|l|}{ Cinsiyet } \\
\hline Erkek & 113 & 27,7 \\
\hline Kadin & 295 & 72,3 \\
\hline \multicolumn{3}{|l|}{ Yaş } \\
\hline $20-24$ & 165 & 40,4 \\
\hline $25-29$ & 118 & 28,9 \\
\hline $30-34$ & 40 & 9,8 \\
\hline $35-39$ & 40 & 9,8 \\
\hline 40 ve Üzeri & 45 & 11,0 \\
\hline \multicolumn{3}{|l|}{ Eğitim Seviyesi } \\
\hline İlköğretim & 3 & 0,7 \\
\hline Lise & 37 & 9,1 \\
\hline Ön Lisans & 192 & 47,1 \\
\hline Lisans & 126 & 30,9 \\
\hline Lisansüstü & 50 & 12,3 \\
\hline \multicolumn{3}{|l|}{ Mesleki Deneyim } \\
\hline 0-1 Y1l & 82 & 20,1 \\
\hline 2-3 Yil & 126 & 30,9 \\
\hline 4-5 Y1l & 47 & 11,5 \\
\hline 6-7 Y1l & 48 & 11,8 \\
\hline 8-9 Y1l & 15 & 3,7 \\
\hline 10 Y1l ve Üzeri & 90 & 22,1 \\
\hline \multicolumn{3}{|l|}{ Hastane Türü } \\
\hline Medipol Mega & 204 & 50,0 \\
\hline Medipol Çamlıca & 104 & 25,5 \\
\hline Medipol Sefaköy & 100 & 24,5 \\
\hline Toplam & 408 & 100 \\
\hline
\end{tabular}

\section{Verilerin İstatistiksel Analizi Sonuçları ve Tartışma}

Verilerin istatistiksel analizinde ilk olarak doğrulayıcı faktör analizi yapılmıştır. $\mathrm{Bu}$ kapsamda öncelikle, model uyum değerlerine bakılmıştır. Materyal ve Metot Bölümü'nde belirtilen model uyum endekslerinin referans değerleri dikkate alınarak yapılan ilk model testinin sonuçları şu şekilde sıralanmıştır:

- $\chi 2 / \mathrm{df}=2,845$

- $\quad$ Ki Kare $=915,954$

- $\quad$ Serbestlik Derecesi=322
- $\mathrm{GFI}=0,856$

- $\mathrm{AGFI}=0,818$

- $\quad \mathrm{NFI}=0,865$

- $\mathrm{CFI}=0,907$

- $\quad$ TLI $=0,891$

- $\quad$ RMSEA $=0,067$

- $\quad \mathrm{SRMR}=0,552$

Yukarıda belirtilen sonuçlara bakıldığında oluşturulan Yapısal Eşitlik Modeli'nin belirli kısımlarında uyum kriterlerinin karşılanmasına rağmen bazılarında da model uyum kriterini karşılamadığı görülmektedir. Model uyumunun iyileştirilmesi adına "Kolaylaştırıcı Koşullar-4", "Fiyat Değeri1", “Alışkanlık-2”, “Alışkanlık-3” öğeleri çıkartılmıştır. Ardından yeniden model uyumu testi yapılmıştır. Yapılan ikinci model uyum test sonuçları aşağıdaki şekilde sıralanmıştır:

- $\chi 2 / \mathrm{df}=2,345$

- $\quad$ Ki Kare $=520,479$

- $\quad$ Serbestlik Derecesi=222

- $\mathrm{GFI}=0,904$

- $\mathrm{AGFI}=0,871$

- $\quad \mathrm{NFI}=0,912$

- $\mathrm{CFI}=0,947$

- $\quad$ TLI $=0,934$

- $\quad$ RMSEA $=0,057$

- $\quad \mathrm{SRMR}=0,446$

İkinci defa yapılan model uyum kontrolünde, bütün model uyum endeksleri değerlerinin referans alınan uyum değerlerini karşıladığı görülmektedir.

Model uyumunun değerlendirilmesinin ardından araştırmada kullanılan değişkenlerin faktör yükleri, AVE, CR ve Cronbach Alpha değerlerinin incelenmesi gerekir. Burada belirtilen değerler Tablo 2'de özetlenmiştir.

Tablo 2'ye bakıldığında araştırmada kullanılan değişkenlerin AVE, CR, Cronbach Alpha değerleri ile değişkenleri oluşturan ifadelerin faktör yüklerinin kriter olarak belirtilen referans rakamlarına uygun olduğu 
görülebilmektedir. Bunun ardından son olarak ayrım geçerliliğinin sağlanıp sağlanmadığı kontrol edilmiş̧ir. Ayrım geçerliliğinin sağlanıp sağlanmadığ değişkenler arasındaki korelasyon durumuna bakılarak incelenmiștir ve bu incelemede elde edilen sonuçlar Tablo 3'te özetlenmiştir.

Tablo 3'e bakıldığında değişkenler arasındaki korelasyon durumunun verilen referans değerinin altında olduğu görülebilmektedir. Burada yapılan incelemelerden elde edilen sonuçların genel olarak manasını açıklamak gerekirse, doğrulayıcı faktör analizi kapsamında yapılan analizler neticesinde, araştırmanın hipotezlerinin test edilmesi için gerek duyulan uygun koşulların sağlandığını göstermektedir. Sağlanan koşullardan dolayı bu kapsamda araştırmada yer alan hipotezlerin testinin uygulanabilmesi için yol analizi yapılmıştır.

Hipotezlerin incelenmesi adına Yapısal Eşitlik Modeli ile yapılan çalı̧̧malarda kullanılan yol analizinin yapılmasıyla beraber elde edilen sonuçlar Tablo 4'te özetlenmiştir.

Tablo 2. Öğelerin ve Değişkenlerin Faktör Yapıları

\begin{tabular}{|c|c|c|c|c|c|c|}
\hline Öğeler & Faktör Yükleri & $\mathbf{M}$ & SD & $\mathbf{C R}$ & AVE & $\alpha$ \\
\hline PB-1 & 0,711 & 4,04 & 0,64 & & & \\
\hline PB-2 & 0,773 & 4,09 & 0,64 & 0,83 & 0,56 & 0,84 \\
\hline PB-3 & 0,783 & 4,06 & 0,66 & & & \\
\hline PB-4 & 0,738 & 3,91 & 0,75 & & & \\
\hline ÇB-1 & 0,661 & 3,98 & 0,72 & & & \\
\hline ÇB-2 & 0,740 & 3,91 & 0,70 & 0,81 & 0,53 & 0,84 \\
\hline ÇB-3 & 0,733 & 3,97 & 0,72 & & & \\
\hline ÇB-4 & 0,778 & 4,06 & 0,69 & & & \\
\hline SE-1 & 0,687 & 3,74 & 0,77 & & & \\
\hline SE-2 & 0,673 & 3,56 & 0,86 & 0,75 & 0,50 & 0,75 \\
\hline SE-3 & 0,760 & 3,83 & 0,78 & & & \\
\hline KK-1 & 0,714 & 4,04 & 0,71 & & & \\
\hline KK-2 & 0,743 & 4,04 & 0,71 & 0,75 & 0,50 & 0,75 \\
\hline KK-3 & 0,682 & 3,92 & 0,77 & & & \\
\hline FD-2 & 0,712 & 3,59 & 0,77 & 0,81 & 0,68 & 0,79 \\
\hline FD-3 & 0,931 & 3,49 & 0,81 & & & \\
\hline HM-1 & 0,912 & 3,47 & 0,91 & & & \\
\hline HM-2 & 0,920 & 3,52 & 0,90 & 0,92 & 0,80 & 0,92 \\
\hline HM-3 & 0,854 & 3,32 & 0,92 & & & \\
\hline AL-1 & 0,760 & 3,65 & 0,94 & 0,73 & 0,58 & 0,73 \\
\hline AL-4 & 0,764 & 3,85 & 0,82 & & & \\
\hline DN-1 & 0,813 & 3,92 & 0,75 & & & \\
\hline DN-2 & 0,736 & 3,62 & 0,90 & 0,85 & 0,66 & 0,84 \\
\hline DN-3 & 0,894 & 3,85 & 0,78 & & & \\
\hline
\end{tabular}

$M=$ Ortalama, $S D=$ Standart Sapma, $C R=$ Bileşik Güvenilirlik, AVE= Ortalama Varyans, $\alpha=$ Cronbach Alpha

Tablo 3. Değişkenler Arası Korelasyon Durumu

\begin{tabular}{|c|c|c|c|c|c|c|c|c|c|c|}
\hline & $\mathbf{M}$ & SD & PB & ÇB & SE & KK & FD & HM & $\mathbf{A L}$ & DN \\
\hline PB & 4,03 & 0,56 & 1 & & & & & & & \\
\hline ÇB & 3,98 & 0,58 & $0,64 * *$ & 1 & & & & & & \\
\hline SE & 3,71 & 0,66 & $0,47 * *$ & $0,39 * *$ & 1 & & & & & \\
\hline KK & 4,00 & 0,60 & $0,66 * *$ & $0,64 * *$ & $0,43 * *$ & 1 & & & & \\
\hline FD & 3,54 & 0,72 & $0,40 * *$ & $0,35^{* *}$ & $0,44 * *$ & $0,41 * *$ & 1 & & & \\
\hline HM & 3,44 & 0,85 & $0,39 * *$ & $0,30 * *$ & $0,43 * *$ & $0,36 * *$ & $0,52 * *$ & 1 & & \\
\hline AL & 3,75 & 0,78 & $0,47 * *$ & $0,46 * *$ & $0,39 * *$ & $0,53 * *$ & $0,44 * *$ & $0,48 * *$ & 1 & \\
\hline DN & 3,80 & 0,71 & $0,53 * *$ & $0,45 * *$ & $0,44 * *$ & $0,54 * *$ & $0,45 * *$ & $0,42 * *$ & $0,65^{* *}$ & 1 \\
\hline
\end{tabular}

M=Ortalama, $S D=$ Standart Sapma, $* * p<0,01$ 
Tablo 4. Yol Analizi Sonuçları

\begin{tabular}{lrrrrr}
\hline Hipotezler & $\boldsymbol{\beta}$ & Std. Hata & $\mathbf{t}$ & $\mathbf{p}$ & Hipotez Sonuçları \\
\hline $\mathbf{H}_{\mathbf{1}}$ & 0,37 & 0,16 & 2,79 & $0,005^{* *}$ & Desteklendi \\
$\mathbf{H}_{\mathbf{2}}$ & $-0,25$ & 0,16 & $-2,02$ & $0,04^{*}$ & Kismen Desteklendi \\
$\mathbf{H}_{\mathbf{3}}$ & 0,05 & 0,08 & 0,76 & 0,44 & Desteklenmedi \\
$\mathbf{H}_{\mathbf{4}}$ & 0,00 & 0,21 & 0,05 & 0,96 & Desteklenmedi \\
$\mathbf{H}_{5}$ & 0,09 & 0,06 & 1,46 & 0,14 & Desteklenmedi \\
$\mathbf{H}_{\mathbf{6}}$ & $-0,13$ & 0,05 & $-2,02$ & $0,04^{*}$ & Kismen Desteklendi \\
$\mathbf{H}_{7}$ & 0,75 & 0,13 & 6,41 & $* * *$ & Desteklendi \\
\hline
\end{tabular}

$* p<0,05, * * p<0,01, * * * p<0,001$

Tablo 4'te belirtilen yol analizi sonuçları neticesinde performans beklentisinin, sağlık çalışanlarının bilgi teknolojileri ve yeniliklerine ilişkin davranışsal tutumları üzerinde anlamlı ve olumlu bir etkiye sahip olduğu bulunmuştur, bundan dolayı $\mathrm{H}_{1}$ kabul edilmiştir $\quad(\beta=0,37, \quad \mathrm{p}<0,01)$. Performans beklentisi, bir kișinin belirli bir sistemi, teknolojiyi kullanması neticesinde iş performansinda avantajlar elde etmesinde yardımcı olabileceğine inanma derecesidir ve inovasyon literatüründeki karşıllğg relatif avantajdır. ${ }^{18}$ Buradaki bulgunun anlamı, sağlık çalışanlarının bilgi teknolojilerinin getirileri ve avantajlarının bulunduğunun farkında olduklarını göstermektedir. İnovasyon açısından düşünüldüğünde ise sağlik çalışanlarının bilgi teknolojileri konusundaki bu bilinci, ilerleyen dönemlerde yapılacak olan yeniliklerin mevcut olan teknolojiden daha iyisi olacağına yönelik inancin bulunduğunu göstermektedir. Burada elde edilen bulgu, literatürde daha önceden yapılan çalışmalarda elde edilen sonuçlarla uyum göstermektedir. ${ }^{19-27}$

Çaba beklentisinin, sağlık çalışanlarının bilgi teknolojileri ve yeniliklerine ilişkin davranışsal tutumları üzerinde anlamlı bir etkisinin olduğu ancak bu etkinin negatif yönlü olduğu bulunmuştur ve $\mathrm{H}_{2}$ bundan dolayı kısmen kabul edilmiştir $(\beta=-0,25$, $\mathrm{p}<0,05)$. Çaba beklentisi, bir kişinin belirli bir sistemi veya teknolojiyi kullanmanın kolay olduğunu algilama derecesidir ve inovasyon literatüründeki karşılı̆̆ı kullanım kolaylı̆̆ıdır. $^{18}$ Buradaki bulgu, sağlık çalışanlarının bilgi teknolojilerini kullanırken belirli zorluklar yaşadıklarını ve bu durumun çalışanları negatif bir şekilde etkilediğini göstermektedir. İnovasyon açısından düşünüldüğünde ise sağlık çalışanlarının kullanmış oldukları bilgi teknolojilerinde kullanım kolaylığının olmamasından dolayı ilerleyen dönemlerde yapılacak yeniliklere ilişkin tutumun olumsuz olma ihtimalini artırabileceğini göstermektedir. Çaba beklentisinin anlamlı bir etki göstermesi literatürde yapılan çalışmalarla uyum göstermektedir. ${ }^{19-21,24-26}$ Fakat bu etkinin negatif yönlü olması literatürde rastlanılmamış bir durumdur. $\mathrm{Bu}$ yönüyle dikkat çekicidir. Çaba beklentisinde böyle bir sonucun ortaya çıkmasının muhtemel sebepleri; çalışanların çalıştıkları kuruluştaki iş süreçlerinin karmaşık olmasından, çalışanların bilgi teknolojileriyle olan etkileşimlerinin yeterli düzeyde olmamasından dolayıdır.

Sosyal etkinin, sağlık çalışanlarının bilgi teknolojileri ve yeniliklerine ilişkin davranışsal tutumları üzerinde anlamlı etkiye rastlanılmamıştır, bundan dolayı $\mathrm{H}_{3}$ reddedilmiştir $(\beta=0,05, p>0,05)$. Sosyal etki, bir kişi için önemli olan bireylerin onun yeni bir teknolojiyi veya sistemi kullanması gerektiğine inandığını algılama derecesidir ve inovasyon literatüründeki karşılığ1 imajdır. ${ }^{18}$ Buradaki bulgu, sağlık 
çalışanlarının bilgi teknolojilerine yönelik davranışsal tutumlarını, başkalarının görüşleri ve tavsiyelerinden etkilenmediklerini göstermektedir. İnovasyon açısından bakıldığında ise sağlık çalışanlarının bilgi teknolojileri ve yeniliklerine yönelik yapılabilecek yeniliklere ilişkin olumlu bir tutuma sahip olmanın, kendilerine belirli bir statü veya ayrıcalık kazandıracağını düşünmediklerini göstermektedir. Elde edilen bu bulgu, literatürde daha önceden yapılan çalışmalarda da bulunmuştur. ${ }^{23,24,27}$

Kolaylaştırıcı koşulların, sağlık
çalışanlarının bilgi teknolojileri ve
yeniliklerine ilişkin davranışsal tutumları üzerinde anlamlı etkiye rastlanılmamıştır, bundan dolayı $\mathrm{H}_{4}$ reddedilmiştir $(\beta=0,00$, p>0,05). Kolaylaştırıcı koşullar, bir kişinin belirli bir sistemin veya teknolojinin kullanımını destekleyecek örgütsel ve teknik bir altyapının bulunduğuna inanma derecesidir ve inovasyon literatüründeki karşılığı uyumluluktur. ${ }^{18}$ Burada elde edilen bulgunun anlamı, sağlık çalışanlarının bilgi teknolojilerini kullanırken örgütsel veya teknik yetersizliklerle karşılaştıklarını göstermektedir. İnovasyon açısından anlamı ise sağlık çalışanlarının kullanmakta oldukları bilgi teknolojilerinin ihtiyaçları ile uyuşmadığını ve bu durumun ilerleyen dönemlerde yapilacak olan yeniliklere yönelik tutumları olumsuz yönde etkileyebilme ihtimali bulunduğunu göstermektedir. Elde edilen bu bulgu, literatürde daha önceden yapilan çalışmalarda da bulunmuştur. ${ }^{23,25,26}$ Kolaylaştırıcı koşullarda bu bulgunun elde edilmesinin muhtemel nedenleri; sağlik çalışanlarının kullanmış oldukları bilgi teknolojilerinin ihtiyaçlarını tam anlamıyla karşılamaması, istemiş oldukları ile kullanilan teknoloji arasinda uyumun olmamasidir.

\begin{tabular}{|c|}
\hline $\begin{array}{l}\text { Algılanan fiyat değerinin, sağlik } \\
\text { lişanlarının bilgi teknolojileri ve } \\
\text { niliklerine iliskin davranıssal tutumları }\end{array}$ \\
\hline
\end{tabular}

herhangi bir teknolojiye yönelik algıladıkları faydalarla bu teknolojiyi kullanmanın parasal maliyeti arasındaki bilişsel değiş tokuştur. ${ }^{9}$ $\mathrm{Bu}$ değişkende elde edilen bulgunun anlamı, sağlik çalışanlarının bilgi teknolojileri ve yeniliklerinden elde etmiş oldukları veya olacakları yararların parasal maliyetten daha büyük ve önemli olduğuna dair bir algının olmadığını göstermektedir. Burada belirtilen bulgu, literatürde daha önceden yapılan çalıșmalarda da bulunmuştur. ${ }^{20,21,24}$ Algılanan fiyat değerinin olumlu ve anlamlı bir etki göstermemesinin muhtemel sebepleri; çalışanların bilgi teknolojilerini kullanırken yaşamış oldukları aksaklıklar ile bu tür teknolojilerin parasal açıdan herhangi bir şey algılamamalarıdır.

Hedonik motivasyonun, sağlık çalışanlarının bilgi teknolojileri ve yeniliklerine ilişkin davranışsal tutumları üzerinde anlamlı bir etkisi olduğu ancak bu etkinin negatif yönlü olduğu bulunmuștur ve $\mathrm{H}_{6}$ kısmen kabul edilmiştir $(\beta=-0,13$, $\mathrm{p}<0,05)$. Hedonik motivasyon, belirli bir teknolojinin veya sistemin kullanımından elde edilen zevk ve eğlenceyi temsil eder. ${ }^{9}$ Burada elde edilen bulgunun anlamı, sağlık çalışanlarının bilgi teknolojileri ve yeniliklerini kullanmanın getireceği avantajlar konusunda belirli bir düzeyde farkındalığa sahip olmasına rağmen avantajlar gibi olumlu durumlar neticesinde ortaya çıkan zevk, keyif alma gibi duyguların yerine bazı mutsuzlukların olabileceğini göstermektedir. Hedonik motivasyonun, davranışsal tutum üzerindeki anlamlı etkisi, literatürde daha önceden yapılan çalışmalarla uyum göstermektedir. ${ }^{20,22-25}$ Fakat hedonik motivasyonun, anlamlı etki göstermesine rağmen negatif etki gösterdiği yalnızca bir çalışmada bulunmuştur. ${ }^{26} \mathrm{Bu}$ çalışmada hedonik motivasyonda böyle bir bulgunun ortaya çıkmasının muhtemel sebepleri; sağlık çalışanlarının bilgi teknolojisinin sağlamış olduğu avantajlardan dolayı duyulan zevk, mutluluk gibi duyguları hissedememeleri ve belirli noktalarda memnuniyetsizliklerin olması, sağlık çalışanlarının sağlıkta kullanılan teknolojilerin öncelikli amacının ihtiyaçları gidermek olarak görmeleri olabilir. 
Alışkanlığın, sağlık çalışanlarının bilgi teknolojileri ve yeniliklerine ilișkin davranışsal tutumları üzerinde anlamlı ve olumlu bir etkiye sahip olduğu bulunmuştur, bundan dolayı $\mathrm{H}_{6}$ kabul edilmiştir $(\beta=0,75$, $\mathrm{p}<0,001)$. Alışkanlık, kişilerin öğrenme nedeniyle bazı davranışlarını otomatik bir şekilde gerçekleştirme eğilimini temsil etmektedir. ${ }^{9}$ Buradaki bulgunun anlamı, sağlık çalışanlarının hem kendilerinin hem de başkalarının sağlık konusundaki ihtiyaçlarını giderirken bilgi teknolojilerini kullanmayı birer refleks haline getirdiklerini göstermektedir. İnovasyon açısından düşünüldüğünde ise sağlık çalışanlarının bilgi teknolojilerine alışık olmalarıyla beraber ilerleyen dönemlerde yapilacak olan yeniliklere de alışı olabilme ihtimallerinin bulunduğunu gösterir. Elde edilen bu bulgu, literatürde daha önceden yapilan çalışmalarda da ulaşılmıştır. ${ }^{21,23,25,26}$

\section{SONUÇ VE ÖNERILER}

Sağlık çalışanlarının bilgi teknolojileri ve yeniliklerini benimsemelerine yönelik davranışsal tutumlarını incelemeyi amaçlayan bu çalışmada, performans beklentisinin ve alışkanlığın davranışsal tutum üzerinde olumlu ve anlamlı bir etkisinin olduğu bulunmuştur. Çaba beklentisinin ve hedonik motivasyonun davranışsal tutum üzerinde anlamlı etkisine rağmen bu etkinin negatif yönlü olduğu tespit edilmiştir. Sosyal etkinin, kolaylaştırıcı koşulların ve algılanan fiyat değerinin ise davranışsal tutum üzerinde anlamlı bir etkisinin olmadığı bulunmuştur. Burada elde edilen sonuçlar, Türkiye'deki sağlik çalışanlarının bilgi teknolojileri ve bu teknolojilere yönelik ileride yapılması planlanan yenilikleri benimseme seviyesinin yukarıya çıkarılması konusunda nelerin üzerinde durulması gerektiği hakkında karar vericileri, yöneticileri bilgilendirmektedir.

$\mathrm{Bu}$ çalışmada olduğu gibi yalnızca belirli boyutlarda davranışsal tutum üzerinde olumlu ve anlamlı bir etkinin olması, sağlık bilgi teknolojileri ve yeniliklerinin başarılı bir şekilde benimsenmesinde yeterli değildir. Buradaki olumlu etkilerin anlamlı olabilmesi için diğer değişkenlerin de olumlu ve anlamlı etki göstermesi gerekir. Bundan dolayı sağlık çalışanlarının bilgi teknolojileri ve yeniliklerini benimsemelerine yönelik davranışsal tutumlarını olumsuz bir şekilde etkileyen etmenlerin iyileştirilmesi gerekir. Araştırmaya katılan sağlık çalışanlarına göre kullanmakta oldukları bilgi teknolojileriyle istenilen düzeyde benimsemenin gerçekleşmemesine neden olan bazı örgütsel ve kullanılan teknolojiye ilişkin teknik faktörlerin bulunabileceğini göstermektedir. Örgütsel ve teknik faktörlere ilişkin araştırmaların yapılması gerekir. Ayrıca sağlık çalışanlarının kullanmakta oldukları bilgi teknolojilerinde ve genel olarak işlerini gerçekleştirirken yaşadıkları sorunların dikkate alınması ve incelenmesi gerekir.

Bütün ülkelerde olduğu gibi Türkiye'de de sağlıkta kullanılmakta olan bilgi teknolojileri ve yeniliklerine yönelik ilerlemeler gerçekleşmeye devam edecektir. Sağlık alanında kullanılmakta olan bilgi teknolojileri gibi mevcut teknolojiler üzerinden yapılacak değerlendirmeler, ileride yapılması planlanan yeniliklerin başarılı bir şekilde uygulanabilmesi için önemlidir. Bu kapsamda UTAUT gibi teknolojiye yönelik tutumları açıklayan teoriler üzerinden çalışmaların yaygınlaşması, sağlık çalışanlarının bilgi teknolojileri dâhil olmak üzere kullanmış oldukları çeşitli teknolojilere ilişkin tutumlarını belirleyen etmenlerin neler olduğu ve bunlara yönelik nelerin yapılması gerektiğini, ilerleyen dönemlerde yapılacak olan yeniliklerin uygulanabilmesi için yapılmas1 gerekenlerin belirlenmesine fayda sağlayacaktır.

$\mathrm{Bu}$ çalışmanın gerçekleşmesi ile beraber ilerleyen dönemlerde, sağlikta bilgi teknolojileri dâhil olmak üzere çeşitli teknolojileri ve yeniliklerine ilişkin davranışsal tutumlarına yönelik incelemelerin artmasına teşvik etmesi ve bu araştırmaların daha derinlemesine değerlendirmelerin yapılması umulmaktadır. 


\section{KAYNAKLAR}

1. Zhou, L.L, Owusu-Marfo, J, Antwi, H.A, Antwi, M.O, Kachie, A.D.T. and Ampon-Wireko, S. (2019). "Assessment of the Social Influence and Facilitating Conditions that Support Nurses' Adoption of Hospital Electronic Information Management Systems (HEIMS) in Ghana Using the Unified Theory of Acceptance and Use of Technology (UTAUT) Model". BMC Medical Informatics and Decision Making, 19, $1-9$.

2. Buabbas, A.J, Sharma, P, Al-Abdulrazaq, A. and Shehab, H (2019). "Smartphone Use by Government Dermatology Practitioners in Kuwait: A Self-Reported Questionnaire Based Cross-Sectional Study". BMC Medical Informatics and Decision Making, 19, 1-11.

3. Maillet, É, Mathieu, L. and Sicotte, C. (2015). "Modeling Factors Explaining the Acceptance, Actual Use and Satisfaction of Nurses Using an Electronic Patient Record in Acute Care Settings: An Extension of the UTAUT". International Journal of Medical Informatics, 84 (1), 36-47.

4. Adenuga, K.I, Iahad, N.A. and Miskon, S. (2017). "Towards Reinforcing Telemedicine Adoption Amongst Clinicians in Nigeria". International Journal of Medical Informatics, 104, 84-96.

5. Sağlık Bakanlığı Sağlık Bilgi Sistemleri Genel Müdürlüğü. (2019). "Sağlık İstatistikleri Y1llı̆̆1 2018". Erisim Adresi: https://sbsgm.saglik.gov.tr/Eklenti/36134/0/siy2018trpdf.pdf (Erişim Tarihi: 11.08.2021).

6. Hennemann, S, Beutel, M.E. and Zwerenz, R. (2017). "Ready for eHealth? Health Professionals' Acceptance and Adoption of eHealth Interventions in Inpatient Routine Care". Journal of Health Communication, 22 (3), 274-284.

7. Eichenberg, C, Wolters, C. and Brähler, E. (2013). "The Internet as a Mental Health Advisor in Germany-Results of A National Survey”. Plos One, 8 (11), e79206.

8. Chang, I.C, Hwang, H.G, Hung, W.F. and Li, Y.C. (2007) "Physicians' Acceptance of Pharmacokinetics-Based Clinical Decision Support Systems". Expert Systems With Applications, 33 (2), 296-303.

9. Venkatesh, V, Thong, J.Y.L. and Xu, X. (2012). "Consumer Acceptance and Use of Information Technology: Extending the Unified Theory of Acceptance and Use of Technology". MIS Quarterly, 36 (1), 157-178

10. Yaşlıoğlu, M.M. (2017). "Sosyal Bilimlerde Faktör Analizi ve Geçerlilik: Kesfedici ve Doğrulayıcı Faktör Analizlerinin Kullanılması". İstanbul Üniversitesi İşletme Fakültesi Dergisi, 46, 74-85.

11. Schermelleh-Engel, K, Moosbrugger, $H$. and Müller, $H$ (2003). "Evaluating the Fit of Structural Equation Models: Tests of Significance and Descriptive Goodness-of-Fit Measures". Methods of Psychological Research Online, 8 (2), $23-74$.

12. McDonald, R.P. and Ho, M.H.R. (2002). "Principles and Practice in Reporting Structural Equation Analyses". Psychological Methods, 7 (1), 64-82.

13. Cangur, S. and Ercan, I. (2015). "Comparison of Model Fit Indices Used in Structural Equation Modeling Under Multivariate Normality". Journal of Modern Applied Statistical Methods, 14 (1), 152-167.

14. Chen, F.F. (2007). "Sensitivity of Goodness of Fit Indexes to Lack of Measurement Invariance". Structural Equation Modeling: a Multidisciplinary Journal, 14 (3), 464-504.

15. Hair, J.F, Anderson, R.E, Babin, B.J. and Black, W.C (2019). Multivariate Data Analysis. Hampshire: Cengage Learning.
16. George, D. and Mallery, M. (2010). SPSS for Windows Step by Step: a Simple Guide and Reference, 17.0 update. Boston: Pearson.

17. Kline, R.B. (2011). Principles and Practice of Structural Equation Modeling. New York: Guilford Publications.

18. Venkatesh, V, Morris, M.G, Davis, G.B and Davis, F.D. (2003). "User Acceptance of Information Technology: Toward a Unified View”. MIS Quarterly, 27 (3), 425-478.

19. Ahmed, M.H, Bogale, A.D, Tilahun, B, Kalayou, M.H Klein, J, Mengiste, S.A. and Endehabtu, B.F. (2020). "Intention to Use Electronic Medical Record and Its Predictors Among Health Care Providers at Referral Hospitals, North-West Ethiopia, 2019: Using Unified Theory of Acceptance and Use Technology 2 (UTAUT2) Model". BMC Medical Informatics and Decision Making, 20, 1-11.

20. Hua, T.V. and Hou, Y. (2020). "Factors That Influence the Intention to Use Self-Diagnosis Apps in Vietnam". Journal of Health, Medicine and Nursing, 72, 47-56.

21. Kunnapapdeelert, S. and Pitchayadejanant, K. (2020). "Hybrid SEM-Neural Networks for Predicting Electronics Logistics Information System Adoption in Thailand Healthcare Supply Chain". International Journal of Business Performance and Supply Chain Modelling, 11 (1), 54-68.

22. Francis, R.P. (2019). "Examining Healthcare Providers' Acceptance of Data From Patient Self-Monitoring Devices Using Structural Equation Modeling With the UTAUT2 Model". International Journal of Healthcare Information Systems and Informatics (IJHISI), 14 (1), 44-60.

23. Owusu Kwateng, K, Appiah, C. and Atiemo, K.A.O. (2021). "Adoption of Health Information Systems: Health Professionals Perspective". International Journal of Healthcare Management, 14 (2), 517-533.

24. Beh, P.K, Ganesan, Y, Iranmanesh, M. and Foroughi, B (2021). "Using Smartwatches for Fitness and Health Monitoring: the UTAUT2 Combined with Threat Appraisa as Moderators". Behaviour \& Information Technology, 40 (3), 282-299

25. Alazzam, M.B, Al-Sharo, Y.M. and Al-Azzam, M.K. (2018) "Developing (UTAUT 2) Model of Adoption Mobile Health Application in Jordan E-Government". Journal of Theoretical \& Applied Information Technology, 96 (12), 3846-3860.

26. Tavares, J. and Oliveira, T. (2017). "Electronic Health Record Portal Adoption: a Cross Country Analysis”. BMC Medical Informatics and Decision Making, 17, 1-17.

27. Jones, M.E. (2013). Factors Supporting the Intention to Use e-Prescribing Systems: Health Professionals' Use of Technology in a Voluntary Setting. Master Thesis, University of the Witwatersrand Faculty of Commerce, Law and Management, Johannesburg. 